\title{
Right sided endocarditis after balloon dilatation of the pulmonary valve
}

\author{
Gurcharan S Kalra, Gurpreet S Wander, Inder S Anand
}

\begin{abstract}
A patient in whom infective endocarditis affecting the pulmonary and tricuspid valves developed after percutaneous balloon dilatation of the pulmonary valve is reported.
\end{abstract}

Percutaneous balloon dilatation is an effective and safe treatment for pulmonary valve stenosis. ${ }^{1}$ We report a case of infective endocarditis of the pulmonary and tricuspid valves after balloon dilatation of a stenosed pulmonary valve.

\section{Case report}

A 38 year old woman presented in exertional dyspnoea (New York Heart Association class III). She was found to have severe stenosis of the pulmonary valve. Echocardiography showed a thickened and doming pulmonary valve. She underwent balloon dilatation. Four inflations were performed with a Mansfield, 9 French, $25 \mathrm{~mm}$ diameter, $3 \mathrm{~cm}$ long balloon catheter. The systolic pulmonary gradient fell from 194 to $63 \mathrm{~mm} \mathrm{Hg}$ after dilatation. There was no pulmonary regurgitation murmur after the procedure. She was discharged from the hospital the next day. On day 15 after the procedure fever developed which responded to a course of antimalarial drugs. Two months later, breathlessness had improved to New York Heart Association class II and a repeat catheter study at this stage showed a peak systolic gradient of $84 \mathrm{~mm} \mathrm{Hg}$ across the pulmonary valve. Repeat dilatation was not attempted. Two weeks after the second catheterisation an intermittent moderate grade fever developed. She complained of anorexia and weight loss. A loud pulmonary regurgitation murmur had developed. Echocardiography showed large mobile vegetations on both the pulmonary and tricuspid valves. Blood cultures for aerobic, anaerobic, and fungal organisms were negative. She was started on a combination of penicillin, cloxacillin, and gentamicin. The fever responded within a week and the antibiotic treatment was continued for six weeks. A repeat catheter study two months after treatment of infective endocarditis showed that the pressure drop across the pulmonary valve was further reduced to $23 \mathrm{~mm} \mathrm{Hg}$. The patient was re- viewed several times in the past year and has remained well.

\section{Discussion}

Infective endocarditis of the pulmonary valve as a complication of balloon dilatation has not been reported before. There is, however, a report of a case of aortic valve endocarditis after balloon dilatation in an immunocompromised patient. $^{2}$ Infective endocarditis is rare in patients with pulmonary stenosis. Johnson et al reported an incidence of 0.2 per 1000 patientyears. ${ }^{3}$ However, studies in animals have clearly established that catheter induced endocardial damage can cause infective endocarditis when animals are bacteraemic. ${ }^{4}$ Moreover, infective endocarditis of the pulmonary valve was common in a necropsy series of patients monitored with a Swan-Ganz catheter. These workers suggested that the infected vegetations were a direct consequence of catheter induced endocardial damage and subsequent bacteraemia. ${ }^{5}$ Stretching and rupture of the valve tissue have been suggested as the mechanisms of the relief of obstruction by balloon dilatation of the pulmonary valve. These could make the valve vulnerable to endocarditis should bacteraemia occur. Our patient did not undergo dental or any other procedure after dilatation of the valve. Endocarditis in her case may have been related to the second cardiac catheterisation study, although bacteraemia seldom occurs during routine cardiac catheterisation.

Pulmonary valve vegetations have seldom been described on echocardiography. First, because pulmonary valve endocarditis is rare and secondly because it is often difficult to visualise the pulmonary valve on echocardiography. ${ }^{6}$ Reports of multiple valve involvement with vegetations on the right side are still rare. The vegetations on the tricuspid valve in our patient could be the result of an extension of infection from the pulmonary valve. The late reduction in the pressure drop across the pulmonary valve after the second catheterisation was probably the result of "medical valvotomy" by infective endocarditis as has been reported before. Although we do not know the source of infection in the present case careful attention to sterile technique and prompt removal of intravenous lines may reduce the frequency of bacteraemia. 
1 Lababidi Z, Wu JR. Percutaneous balloon pulmonary valvuloplasty. Am J Cardiol 1983;52:560-5

2 Cujec B, McMeekin J, Lopez J. Bacterial endocarditis after percutaneous aortic valvuloplasty. Am Heart $J$ 1988; 115:178-9.

3 Johnson DH, Rosenthal A, Nadas AS. A forty year review of bacterial endocarditis in infancy and childhood. Circulation 1975;51:581-90.

4 Garrison PK, Freedman LR. Experimental staphylococcal endocarditis in rabbits resulting from placement of polyethylene catheter in the right side of the heart. Yale $J$ Biol Med 1970;42:394-410.

5 Rowley KM, Clubb KS, Smith GJW, Cabin HS. Right sided infective endocarditis as a consequence of flowdirected pulmonary artery catheterisation. $N$ Engl J Med 1984;311:1152-6.

6 Nkamura K, Satoni G, Sakani T, et al. Clinical and echocardiographic features of pulmonary valve endocarditis. Circulation 1987;67:198-204.

\section{VIEWS FROM THE PAST Paul Rothschild}

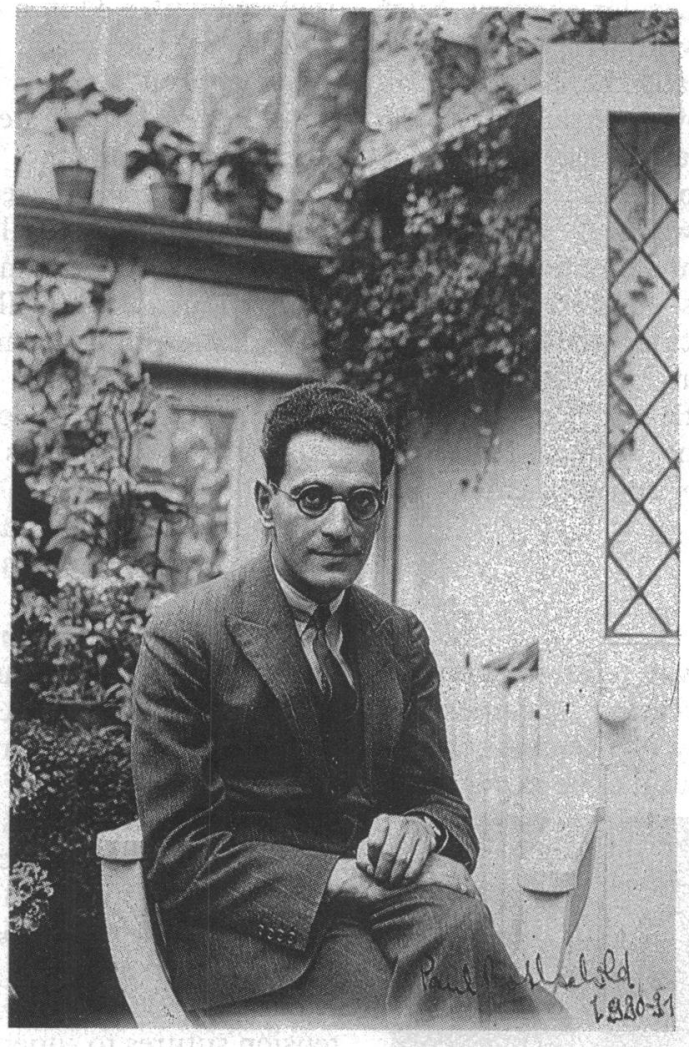

Rothschild's promising German academic career was cut short when Hitler rose to power. He had spent two years in England as a postgraduate and with Lewis wrote papers on intermittent claudication and ischaemic paralysis of nerves. Lewis warned him of the Nazi danger looming; after he had returned to Frankfurt he received a telegram from Lewis offering him a base at University College Hospital and brought his family over. He subsequently entered general practice, also serving in the Royal Army Medical Corps. After his death in 1965 distinguished contemporaries including A V Hill and Sir George Pickering wrote in glowing terms of his abilities and distinction (Lewis collection).

DENNIS M KRIKLER 